third letter in a three-letter word starting with d. However, another 3.26 reaction time was found for:

PIG PAN POT PRY PEW PUP

PRO PAD PEA PIG PAR PUS

The correct word is pig. This word is a popular word with relatively high probability of letter frequency. If infrequent words would distract by drawing attention, this card should have produced a slow reaction time.

The 10.38-sec reaction time was obtained for a card with the following:

\section{GAB GEL GOD GUN GIG GET GIG GUM GUY GAS GEE GAP}

To some extent, the long reaction time for this card is probably a function of the placement of GIG in the 5-1 position. In itself, it is not a common word, but it is in the context of another very uncommon one, i.e., GEL. In contrast, one stimulus card with a 3.26 median time occurred in a 6-2 position and contained:

\section{LIP LOW LAC LAY LAB LOG \\ LFI LOG LOT LAD LEE LOP}

Lac, lei, and lee might be classified as relatively uncommon in both language and letter combinations.

Future research will investigate the part played by word frequency and letter

Table 2

Median Reaction Times for Individual Cards (Condition A-First Letter Same)

\begin{tabular}{|c|c|c|c|c|}
\hline \multicolumn{2}{|c|}{$\begin{array}{l}\text { Position of } \\
\text { Search Word }\end{array}$} & \multirow[b]{2}{*}{ Target } & \multirow[b]{2}{*}{$\mathrm{Mdn}$} & \multirow[b]{3}{*}{ Range } \\
\hline $\begin{array}{l}\text { First } \\
\text { Line }\end{array}$ & Second & & & \\
\hline Line & & Word & RT & \\
\hline 1 & 4 & act & 5.24 & $1.08-30.16$ \\
\hline 1 & 4 & rim & 4.63 & $1.21-10.08$ \\
\hline 1 & 4 & pig & 3.26 & $1.19-24.04$ \\
\hline 1 & 5 & nag & 4.09 & $1.05-19.54$ \\
\hline 1 & 5 & duo & 3.00 & $.97-31.53$ \\
\hline 1 & 6 & cud & 5.28 & $1.05-20.89$ \\
\hline 1 & 6 & oil & 5.97 & $1.05-14.41$ \\
\hline 2 & 5 & sob & 6.45 & $2.04-16.58$ \\
\hline 2 & 5 & why & 5.08 & $1.79-32.37$ \\
\hline 2 & 6 & fry & 6.52 & $1.83-16.01$ \\
\hline 2 & 6 & ply & 5.65 & $2.78-41.65$ \\
\hline 3 & 6 & hem & 4.66 & $1.95-29.61$ \\
\hline 3 & 6 & hay & 5.23 & $1.51-15.43$ \\
\hline 4 & 1 & fad & 5.18 & $1.09-19.94$ \\
\hline 4 & 1 & toe & 5.68 & i. $17-18.75$ \\
\hline 5 & 1 & doe & 6.13 & $1.77-15.06$ \\
\hline 5 & 1 & gig & 10.38 & $3.26-29.25$ \\
\hline 5 & 2 & $\mathrm{cab}$ & 6.47 & $3.21-25.71$ \\
\hline 5 & 2 & bus & 7.31 & $1.20-65.49$ \\
\hline 6 & 1 & rut & 5.54 & $1.91-23.71$ \\
\hline 6 & 1 & mug & 5.99 & $1.98-14.14$ \\
\hline 6 & 2 & tug & 6.47 & $2.98-26.94$ \\
\hline 6 & 2 & $\log$ & 3.26 & $1.95-32.62$ \\
\hline 6 & 3 & sag & 5.59 & $1.50-10.60$ \\
\hline 6 & 3 & elf & 6.39 & $3.47-11.67$ \\
\hline
\end{tabular}

frequency. The position of the frequent or nonfrequent words or letter frequencies in relation to the key word should also be investigated. Lei and lee may not even be important as distractors, since they are in the second line in the example above.

It would seem that there may be a simple "template matching," but the content of the array and the formation of the target in relation to the array leads to some degree of facilitation or inhibition of response speed.

\section{REFERENCES}

MAYZNER, M. S., TRESSELT, M. E., \& PEZENIK, J. A study of detection, search. matching, and memory functions. Psychonomic Science, 1968, 10, 217-218.

NEISSER, U. Visual search. Scientific American, $1964,210,94-102$.

NEISSER, U., NOVICK, B., \& LAZAR, R. Searching for ten targets simultancously. Perception \& Motor Skills, 1963, 17, 955-961. SIEGEL, S. Nonparametric statistics for the behavioral sciences. New York: McGraw-Hill 1956.

\title{
Short-term temporal stability of interpersonal attraction $^{1}$
}

\section{WILLIAM GRIFFITT and PAUL NELSON, Kansas State University, Manhattan, Kans. 66502}

The temporal stability of attitude-evoked attraction responses and the similarity-attraction relationship were examined across a l-week time interval. In the absence of additional information concerning a stranger, attraction toward the stranger was found to be highly stable $(p<.001)$. In addition, the positive relationship between similarity and attraction was found to be quite stable $(p<.01)$ across this time period.

Experimental work on interpersonal attraction (Byrne, 1969) and impression formation (Anderson, 1968) is commonly characterized by a laboratory situation in which Ss are exposed to a series of stimuli attributed to or associated with a target person. Ss are then asked to rate the target person on one or more such evaluative dimensions as attraction, attractiveness, or competency. Under such conditions, investigators have typically examined the relationship between linear combinations of differentially weighted positive and negative stimulus components and initial evaluative impressions or judgments concerning the target person (Griffitt, Byrne, \& Bond ${ }^{2}$ ). Some investigators have attempted to investigate systematic sequential changes in evaluative impressions as a function of sequentially presented attitudinal stimuli and sequential assessment of attraction responses (Byrne, Lamberth, Palmer, \& London, in press) as well as systematic response variability as a function of sequential presentation of adjective stimuli (Stewart, 1965).

The relationship between attitude similarity and attraction is well established.
Attraction toward a stranger is consistently found to be a positive linear function of the proportion of attitudes expressed by the stranger that are similar to those of the S (Byrne, 1969). Little is known, however, concerning either the temporal stability of attraction responses or the temporal stability of the similarity-attraction relationship under conditions in which $S$ is exposed to no additional information concerning the target person. When repeated contact and communication are possible, Newcomb (1961) has reported that attraction stabilizes at relatively early stages of acquaintance, and that the similarity-attraction relationship increases in magnitude over time. On the other hand, Kerckhoff \& Davis (1962) have reported that value similarity and courtship progress were positively related for short-term dating couples but not for long-term dating couples. Levinger \& Breedlove (1966) have attributed the latter finding to the decreasing instrumentality of generalized value consensus in the advanced stages of courtship.

The present investigation was designed primarily to examine the temporal stability of attraction responses and of the similarity-attraction relationship when Ss have no opportunity to acquire additional information concerning the target person. METHOD

The Ss for the experiment were 22 introductory-psychology students at Kansas State University who had been pretested on a 12-item attitude questionnaire similar to those utilized in earlier research (Griffitt \& Byrne, in press). Approximately 2 to 3 weeks following the initial testing, each $\mathbf{S}$ was requested to listen to the tape-recorded responses of an anonymous same-sex stranger to the same attitude questionnaire utilized in 
pretesting. After listening to the opinions of the anonymous stranger, each $\mathrm{S}$ was asked to evaluate the stranger on the Interpersonal Judgment Scale (IJS), the last two items of which are summed to yield the dependent measure of attraction, which ranges from 2 (least positive) to 14 (most positive) and has a split-half reliability of .85 (Byrne \& Nelson, 1965). Twelve Ss responded to a stranger who agreed with them on .25 of the issues, while the remaining $10 \mathrm{Ss}$ listened to and evaluated a stranger who agreed with them on .75 of the issues. The tape-recorded responses were, of course, bogus ones simulated by $E$ according to the "unique-stranger" technique (Griffitt \& Byrne, in press). Following assessment of this initial attraction response (A1), each S was scheduled to take part in a second unrelated experiment (concept formation) that was being conducted exactly 1 week later. After participating in the second experiment, each $\mathrm{S}$ was reminded of his participation in the earlier experiment and was asked to again evaluate the stranger on the IJS (A2) and then to fill out the 12-item attitude scale as he recalled the stranger had responded on the tape.

\section{RESULTS AND DISCUSSION}

The means of the attraction responses as a function of time of assessment (A1 and A2) and proportion of similar at titudes are shown in Table 1. To examine the temporal stability of attraction responses, the correlation between $\mathrm{A} 1$ and $\mathrm{A} 2$ was determined and found to be $.82(p<.001$, $\mathrm{df}=20) .{ }^{3}$ It appears that, in the absence of additional information concerning a stranger, attraction toward the stranger is quite stable, at least over a 1-week interval.

With respect to similarity and attraction, the correlation of $.59(\mathrm{p}<.001, \mathrm{df}=20)$ between initial attraction (A1) and the experimentally created proportion of similarity variable in the initial session (P1) replicated numerous earlier demonstrations of the positive relationship between the two variables (Byrne, 1969). Further, the stability of this relationship is illustrated by the correlation between $\mathrm{Pl}$ and $\mathrm{A} 2$ $(\mathrm{r}=.49, \mathrm{p}<.01, \mathrm{df}=20)$. Following a 1 -week interval, experimentally created proportion of similarity continued to exert a significant influence on attraction responses.

Table 1

Mean Attraction Responses as a Function of Time of Assessment and Proportion of Similar Attitudes

\begin{tabular}{crr}
\hline & \multicolumn{3}{c}{ Time } \\
Proportion & A1 & A2 \\
\hline .25 & 8.83 & 8.67 \\
.75 & 11.50 & 10.80 \\
\hline
\end{tabular}

By comparing each S's responses to the 12-item attitude scale as he recalled the stranger had responded with each S's own responses to the scale at the time of pretesting, it was possible to determine the proportion of experimentally created similarity recalled by each $\mathrm{S}$ during the second (P2) session. The correlation between $\mathrm{P} 1$ and $\mathrm{P} 2$ of $.83 \quad(p<.001$, $\mathrm{df}=20$ ) indicates that $S s$ were quite accurate in recalling the stranger's responses following the 1 -week interval. It seems reasonable that attraction responses assessed during the second session (A2) would be more closely related to $\mathrm{P} 2$ than to $P 1$ if $P 2$, as opposed to $P 1$, is considered as the "effective proportion" of similarity during the second session. The correlation between $\mathrm{A} 2$ and $\mathrm{P} 2$ is, however, somewhat smaller $(r=.41, p<.05, \mathrm{df}=20)$ than the A2-P1 relationship reported above. The less-than-perfect stabilities of attraction responses (.82) and recalled proportions (.83), however, may account for the reduced magnitude of the $A 2-\mathrm{P} 2$ relationship.

An additional stimulus variable, not yet considered, was also related to attraction responses. As described elsewhere (Griffitt \& Byrne, in press), within the present similarity-attraction paradigm, a similar attitudinal response is defined as a response one scale point away from S's response but on the same side of the neutral attitudinal point as S's response. A dissimilar response is defined as one that is three points discrepant from S's response on the opposite side of the neutral point. Thus, each $S$ is exposed to at least two attitudinal stimulus dimensions-proportion of similar responses and response discrepancy. Under certain circumstances (Griffitt \& Byme, in press), these two dimensions are totally dependent $(r=-1.00)$, while under other circumstances, the two dimensions are partially independent. It has been demonstrated (Byrne, Clore, \& Griffitt, 1967) that attraction responses are jointly and independently affected by both discrepancy and proportion of similarity. In the present investigation, experimentally created proportion of similarity (P1) and attitudinal discrepancy (D1) were, in fact, perfectly related $(\mathrm{r}=-1.00)$. In the manner described above concerning P2, D2 or "recalled-discrepancy" scores were computed for each S. D1 and D2 scores were highly related as indicated by the correlation of $.77(\mathrm{p}<.001, \mathrm{df}=20)$. In addition, the relationship between $A 2$ and D2 was of borderline significance $(.05<\mathrm{p}<.10)$.

While earlier work (Griffitt \& Byrne, in press) has demonstrated the temporal stability of stimulus dimensions utilized in attitude-similarity and attraction investigations, the present findings indicate that attitude-evoked attraction responses are highly stable over a 1-week interval, and that the stimulus-response relationship remains substantially unchanged over this time interval. Also suggested by the P1-P2 and D1-D2 correlations is that Ss attend closely to the stimulus presentations in such experiments in that they are able to recall the stranger's attitudes quite accurately following a 1 -week interval.

It is not contested, of course, that exposure to additional information concerning a target person is likely to alter systematically one's initial impression of the person. It is significant, however, that, in the absence of additional information, initial impressions are highly stable at least over the time period involved in the present experiment.

\section{REFERENCES}

ANDERSON, N. H. A simple model for information integration. In R. P. Abelson, E. Aronson, W. J. McGuire, T. M. Newcomb, M. J. Rosenberg, and P. H. Tannenbaum (Eds.), Theories of cognitive consistency: $A$ sourcebook. Chicago: Rand McNally, 1968. Pp. 731-743.

BYRNE, D. Attitudes and attraction. In $\mathbf{L}$. Berkowitz (Ed.), Advances in experimental social psychology. Vol.4. New York Academic Press, 1969. Pp, 35-89.

BYRNE, D., CLORE, G. L., GRIFFITT, W. Response discrepancy versus attitude similarity-dissimilarity as determinants of attraction. Psychonomic Science, 1967, 7, 397-398.

BYRNE, D., LAMBERTH, J., PALMER, J., \& LONDON, O. Sequential effects as a function of explicit and implicit interpolated attraction responses. Journal of Personality \& Social Psychology, in press.

BYRNE, D., \& NELSON, D. Attraction as a linear function of proportion of positive reinforcements. Journal of Personality \& Social Psychology, 1965, 1, 659-663.

GRIFFITT, W., \& BYRNE, D. Procedures in the paradigmatic study of attitude similarity and attraction. Representative Research in Social Psychology, in press.

KERCKHOFF, A., \& DAVIS, K. E. Value consensus and need complementarity in mate selection. American Sociological Review, 1962, 27, 295-303.

LEVINGER, G., \& BREEDLOVE, J. Interpersonal attraction and agreement: $A$ study of marriage partners. Journal of Personality \& Social Psychology, 1966, 3, 367-372.

NEWCOMB, T. M. The acquaintance process. New York: Holt, Rinehart \& Winston, 1961.

STEWART, R. H. Effect of continuous responding on the order effect in personality impression formation. Journal of Personality \& Social Psychology, 1965, 1, 161-165.

$$
\text { NOTES }
$$

1. This research was supported in part by Research Grant MH 16351-01 to the first author from the National Institute of Mental Health, United States Public Health Service.

2. Griffitt, W., Byme, D., \& Bond, M. Proportion of positive adjectives and personal relevance of adjectival descriptions as determinants of attraction. Unpublished manuscript, 1969.

3. Significance levels are for one-tailed tests. 